Acta Poetica $35 \cdot 2$

JULIO-DICIEMBRE

$2014(69-81)$

\title{
Poética musulmana: Cantos a la amada de Muahmmud Ibn Al-Mahad
}

\author{
Reyna Carretero Rangel
}

El propósito de este artículo es compartir el develamiento de los cantos místicos del poeta musulmán Muahmmud Ibn Al-Mahad. Sus versos nos develan nuestra ancestral riqueza poética y mística, puesto que el legado musulmán, al igual que el griego y el hebreo forman parte de nuestra matriz civilizatoria. El poeta uruguayo Saúl Ibargoyen a través de la identidad narrativa de Al-Mahad, a quien nos presenta como ese Otro yo en sí mismo, ha configurado un tipo muy especial de espejo poético, cercano a un palimpsesto sui géneris donde encontramos los signos de una escritura eterna. Reconocemos en su poética las profundas huellas del conocido poeta Sufi Yalal ad-Din Muhammad Rumi, quien expresó en sus versos la unión con el Amado, el "Uno Perfecto". También percibimos la sutil fragancia de Ibn 'Arabî, llamado Shaykh al-Akbar, el "Maestro más grande", quien nos dio el regalo de la "unidad de la esencia divina". El Ser Real es incomparable y trascendente, mas él se devela como manifestación divina (tajallí) en todas las cosas del mundo. De ahí que la poesía de Al-Mahad configure esta relación entre el amor y la unidad para expresar con total sutileza la pasión por la Amada, como apreciamos en este poema: "En el libro venido de lo más Alto también está escrito el silencio del ardor que cruza por tu pecho. Ama a la amada con ese silencio y el libro tendrá nuevas palabras para ti”.

PAlabras Clave: Ibn Al-Mahad, Poética musulmana, La Amada, Libro Sagrado.

The purpose of this article is to share the discovery of the mystical songs of muslim poet Muahmmud Ibn Al-Mahad. His poems disclose our poetic and mystical ancestral wealth, since the Muslim legacy, as well as the Greek and Hebrew, are part of our civilization matrix. The uruguayan poet Saúl Ibargoyen through 
the narrative identity of Al-Mahad, whom unveils as one Other on himself, has configured a very special kind of poetic mirror, close to a palimpsest sui géneris where we find the signs of an eternal scripture, which approach us to the Beloved woman's beauty and the desert as images of the mystical experience. In the Al-Mahad' songs we find out the profound traces of the well-known Sufi poet Yalal ad-Din Muhammad Rumi, who expressed in his verses the union with his beloved (tawhid) the Perfect One. Also we perceive on his poems the delicate fragrance of Ibn "Arabî, called al Shaykh al-Akbar, "The Great Master", who gaves us the gift of the "unity of the divine Essence". The Real Being is incomparable and transcendent, but unveils itself as divine manifestation (tajallí) in all things. Thus, Al-Mahad's verses configure this relation between love and unity to express with all subtleness the passion for the Beloved woman, as we appreciate in this poem: "In the book came from the Highest, is written also the silence of the zeal that cross your heart. Love the Beloved woman with that silence and the book will have new words for you".

KEYwORDS: Ibn Al-Mahad, Muslim poetic, The Beloved woman, The Sacred book.

Fecha de recepción: 9 de octubre de 2013

Fecha de aceptación: 20 de enero de 2014 


\author{
Reyna Carretero Rangel \\ Universidad Nacional Autónoma de México \\ Facultad de Ciencias Políticas y Sociales
}

\title{
Poética musulmana: Cantos a la amada de Muahmmud Ibn Al-Mahad
}

Como preludio a nuestro estudio he aquí un canto de Muahmmud Ibn Al-Mahad de su obra Cantos a la amada:

\author{
En el Libro venido de lo alto \\ también está escrito el silencio \\ del ardor que cruza por tu pecho. \\ Ama a la amada con ese silencio \\ y el Libro tendrá \\ nuevas palabras para ti
}

(Al Mahad 52).

Como introducción a la poesía de Al-Mahad, quisiera compartir con ustedes algunas consideraciones derivadas de su abordaje: en primer lugar, que la poesía musulmana se devela como una narrativa que también nos es propia, tanto como la tragedia griega y la profética hebrea. Lo "árabe-musulmán" pensado como lo "oriental", tal como lo estudió tan profusamente Edward Said en su obra Orientalismo es para Occidente: "la fuente de sus civilizaciones y sus lenguas, su contrincante cultural y una de sus imágenes más profundas y repetidas de Lo Otro [...] Sin embargo, nada de este Oriente es puramente imaginario. Oriente es 
una parte integrante de la civilización y de la cultura material europea" (19-20); y nosotros añadiríamos que también de América Latina, y el mundo entero.

De ahí que no exista una separación cultural o civilizatoria, sino por el contrario, una continuidad estrecha entre la "filosofía profética", en tanto "filosofía narrativa" primordial (Corbin, La imaginación creado$r a, 25)$, narrada en la Biblia hebrea, en el Nuevo Testamento cristiano, y en el libro sagrado del Islam, $A l$ Qur'an (nombre que proviene de la raíz: recitar, leer, y se connota con explicación, estudio, investigación). En la narrativa musulmana se relata que El Corán le fue revelado a Muhammad durante los últimos veintitrés años de su vida, aprendido y recitado de memoria por sus seguidores; y a los pocos años de su muerte, escrito y diseminado por todo el mundo a través de la rápida expansión del imperio musulmán.

De esta filosofía profética se deriva la narrativa teofánica del sufismo (tasawuf), la vía exaltada del Islam, fundamental para comprender la experiencia mística, en tanto representa la lucha espiritual (jihad), que exige la purificación del espíritu por medio de la contemplación (mushahada), y de la invocación a Dios (dhikr). Se trata, sobre todo, de una experiencia interna que intenta ser congruente con una forma de vida. Es al mismo tiempo una "peregrinación en las profundidades" que aspira a lo más alto: ínstasis en el que se ilumina la presencia de Dios, y salida de sí mismo en Dios por medio del éxtasis (cfr. Chevalier, El sufismo).

La expresión al sufi se encontró por primera vez en 776 d.C., y se le atribuye a un asceta iraquí. Su origen etimológico está relacionado con la raíz árabe suf (lana). El sufí utiliza un vestido de lana como signo exterior de pobreza (fakhir) y desapego interior. Existe otra relación etimológica con la palabra árabe safa, safua (pureza). "Al conquistar el desapego, el sufí purifica sus deseos más secretos" (Chevalier, El sufismo, 10).

Ahora bien, ya inmersos en el horizonte místico musulmán del siglo XII y XIII, es muy posible que Ibn Al-Mahad tuviera una influencia importante del más grande poeta que ha cantado al Amado: Yalal ad-Din Muhammad Rumi, quien nació en Balj (Balkh), Afganistán, en 1207, y vivió la mayor parte de su vida en Konya, Turquía. La suya es una expresión excelsa sobre la Unidad amorosa entre "amante y amado", de- 
velada ante sus ojos a través del encuentro con el monje errante Shams, originario de Tabriz, ciudad ubicada al noroeste de Irán. Como se dice en la tradición sufí, fue un "encuentro entre dos océanos", por su inmensidad y elevación mística a través de la experiencia del amor absoluto al Amado. Shams de Tabriz fue un "sol espiritual" en la vida de Rumi. Este amor que surgió entre los dos fue tan grande que Rumi le dedicó a Shams todo un libro de 3,239 versos: el Diwan de Shams de Tabriz (Colección de poemas). Una muestra son estos versos fundamentales:

No soy de Adán, ni de Eva, ni del Edén y Rizwan.

Mi lugar es lo Sin Lugar; mi huella es lo Sin Huella,

No es cuerpo ni alma, pues pertenezco al alma del Amado.

He alejado la dualidad, he visto que los dos mundos son uno;

Busco al Uno, conozco al Uno, veo al Uno, llamo al Uno...

Estoy embriagado con la copa del Amor, he perdido de vista a

los dos mundos...

... Estoy tan embriagado en este mundo,

Que salvo de embriaguez y jolgorio no tengo nada de que hablar

(Diwan, 125-127).

A su vez es muy interesante que también Rumi, siendo uno de los mayores teólogos y sabios de su tiempo, recibió una influencia importante del sheikh al-Akbar, Ibn 'Arabî, a través del hijastro de éste: Sadroddîn Qunawî (1274). Ibn 'Arabî es considerado "el más grande maestro" sufi; nació en Murcia, España, en 1165, místico sufí, filósofo, poeta y viajero. Entre sus más grandes obras, traducidas afortunadamente al español, encontramos: Al-Futuhat al-Makkiyya (Las revelaciones de la Meca), Fusus al-Hikam (Los engarces de la sabiduría), así como el Libro del Tesoro de los amantes; y en particular, su Tratado de la Unidad.

La obra de Ibn 'Arabî abrió la puerta de entrada al avizoramiento de la Unidad, que está oculta al pensamiento de la dualidad, basado en la creencia de que lo divino está separado de nosotros. Ibn 'Arabi nos enseña que es en el tránsito del éxtasis místico donde se nos devela la Unidad, la no separación, porque "no hay diferencia entre El que envía 
el mensaje, el mensaje y del destinatario del mensaje" ("Arabî, Tratado de la Unidad, 19). El gran obsequio que en su tratado sobre la Unidad nos hace es el reconocimiento de que las cualidades más excelsas atribuidas a Dios son atributos que poseemos todos porque en la Unidad no hay distintas existencias, como apasionadamente nos lo dice:

Todos los atributos de Alá son tus atributos. Verás que tu exterior es el Suyo, que tu interior es el Suyo, que tu comienzo es el Suyo y que tu fin es el Suyo. Verás que tus cualidades son las Suyas y que tu naturaleza íntima es la Suya. Y eso sin que te conviertas en Él, o que Él se convierta en ti, sin transformación, sin disminución o aumentación alguna (31).

Henry Corbin señala que las distintas formas que toman las obras, tanto sobre la manifestación espiritual de Ibn 'Arabî como la de Rumi, tienden a la misma: "conspiración de lo visible y lo invisible, de lo físico y lo espiritual, en una unión mística en la que el Amado se convierte en el espejo que refleja el rostro secreto del amante místico, mientras que éste, purificado de la opacidad de su ego, se convierte recíprocamente en el espejo de los atributos y las acciones del Amado" (88-89).

Esta brevísima introducción nos permite abordar con más confianza el paisaje místico de Muahmmud Ibn Al-Mahad, poeta musulmán del siglo XIII, nacido probablemente en Bagdad en 1258, o en Damasco; no lo sabemos, porque como nos advierte su "descubridor" y traductor al español, el poeta uruguayo Saúl Ibargoyen, "la información sobre su vida es escasísima". Su residencia parece haber sido cerca de El Cairo, Egipto, aunque también se encuentran sus huellas en Sevilla: "se detuvo en Samarra, donde, desde un alminar del periodo abbasí, midió la imposible distancia de todos los desiertos; [...] fue huésped de Granada (adonde llegó antes de que nacieran los leones de la Alhambra)" (Ibargoyen, Cantos a la amada, 12-13).

Los recovecos de su vida se nos presentan como meros destellos deslumbrantes y efímeros; sin embargo, lo que sí se ha podido retener de él es el núcleo de su poética, en la que encontramos, de acuerdo con Ibargoyen: "un combate interior entre la Hakika (verdad) y la Sharia (ley) del que resultaría un ascetismo espiritualizado por la unidad erótica mujer/amada $=$ hombre/poeta, en busca de la unicidad cósmica" 
(14-15). Sobresale, en particular, su entrega total, tierna y devota a la Amada: "Al-Mahad otorgó a la mujer real y cotidiana una atención lírica desusada, en la poesía arábigo-islámica" (20). Y sí, efectivamente, sus Cantos a la amada difieren, en la manifestación apasionada, por ejemplo, de este poema de Al-Walid Ibn Yazid (m. 744 d.C.) dedicado a su prima y esposa, Salmà, quien murió siendo aún joven:

Un día me dijeron que Salmà había salido a rezar.

Un gracioso pájaro miraba desde la rama

Y le pregunté: "Quién conoce a Salmà".

"Yo", y se echó a volar.

"Acércate a mí".

"Aquí estoy”, y bajó.

“HHas visto a Salmà?”

"Sí", y huyó.

Me hirió en lo más íntimo del corazón

Y voló

(Ibn Yazid, “Diálogo”, 28).

La poesía de Al-Mahad “es una novedosa, para su tiempo, y polémica preceptiva poética", nos dice Ibargoyen. Esto es evidente si consideramos que frente a los dos tipos comunes de expresión en la mayoría de las lenguas, a saber: prosa y poesía, en el árabe se añade la prosa rimada. Sin embargo, la poesía de Al-Mahad contraviene los dieciséis metros codificados de al-Jalil ibn Ahmad, que desde entonces han permanecido invariables de acuerdo con Heikal (Alifnûn). Al-Mahad "combina los ocho pies y el recurso monorrimo y de rima alternada", y sus "cantos o canciones", como solía llamarle algunas veces, están incompletos, con lo que, de acuerdo con la interpretación de Ibargoyen, "posiblemente trataba de demostrar lo inacabado de cualquier empresa humana" (Cantos a la amada, 14, 18).

Sus poemas también son una constante mística de la dignidad y de la sutileza conferida al ser humano en el Islam. Ibn 'Arabi relata que el humano es llamado Califa (representante divino) en tanto Dios preserva su creación a través de él, tal como el sello preserva sus tesoros. En tanto el sello del Rey esté sobre él, nadie osará abrirlo excepto con su 
permiso. Lo designó como Califa para la preservación del cosmos, y el cosmos no terminará en tanto el ser humano perfecto permanezca en él.

A esta dignidad conferida desde lo más Alto, corresponde una "Poética de la sutileza" como complemento indispensable; una narrativa de la "dignidad-sutileza", como cortesía espiritual (al-udaba) que responde al atributo divino de la sutileza (Al-Latif): “Abd al-Latíf es aquél cuyo fino ojo interno es abierto para ver la belleza interior en todo. De esta manera él mismo recibe belleza y se relaciona bellamente con toda la creación, haciéndola bella" (Al-Jerrahi, Los Más Bellos Nombres de Allah). En este extenso poema, Al-Mahad lo recita así:

Debajo de la primera piel de la amada puedes lamer con tus menguados ojos algo apenas de la hermosura de sus huesos: pétalos transparentes que una suavísima sangre sostiene.

Por qué esos pétalos ahí, te preguntas.

Por qué envueltos en tan cálidas sustancias que al igual que un mugiente cuerpo fueron forjadas con agua y con tierra. Te preguntas quién se abrazará a esos pétalos blancos, quién entre su aroma quemante habrá de nacer y morir.

Al-Mahad escucha las voces: para qué te exiges ahora una respuesta si jamás pudiste contestar una sola pregunta (Al Mahad, en Ibargoyen, Cantos, 85).

La "Amada" en Al-Mahad es el Bien Infinito, así como configuración perenne del sentido trascendente, teofánico y eterno, volcado en la fragilidad que nos con-voca y pro-voca el llamado de la delicadeza y la ternura ante la dignidad translúcida de lo femenino. La sutileza de los Cantos a la amada de Al-Mahad, también la podemos pensar como "ternura" que despliega una connotación de significados tales como dulzura, delicadeza, afectividad, cariño, benevolencia, benignidad: "una ce- 
lebración mística del "sueño de Dios"” (Rochetta, Teología de la ternura, 11). La manifestación de la dignidad-sutileza es susceptible de manifestarse como caricia que va más allá del contacto sensible: "consiste en no apresar nada, [...] En cierto sentido expresa el amor, pero sufre por su incapacidad de decirlo. Tiene hambre de esta expresión misma, en un incesante crecimiento del hambre" (Levinas, Totalidad e infinito, 267-268).

Los siguientes versos reflejan esta delicadeza y sutileza de los Cantos a la amada de Al-Mahad:

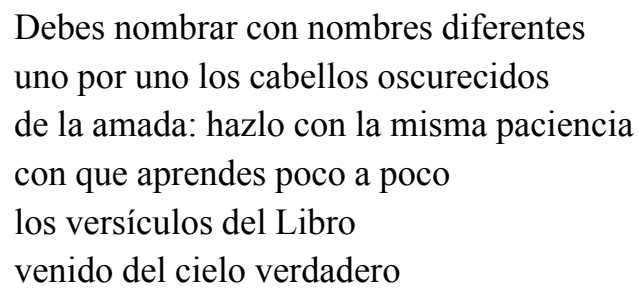

La característica más relevante en su obra es descrita por el mismo Al-Mahad en su Tratado de la soledad de la palabra: "Cada palabra alcanza doble sacralidad: una primera, derivada del Gran Libro que Allâh no necesita escribir, y una segunda, formada por el encuentro de la primera con la apagada y dividida lengua de las mujeres y los hombres, que así despierta y se ilumina en el Único Verbo" (23). En este sentido, es muy probable que Al-Mahad haya padecido en alguna medida el suplicio de Al-Hallaj, quien en el estado de aniquilamiento y entrega total en Allâh (fanâ fi-lâh) se fundió en la Unidad con el Amado de tal forma que su exclamación Anâ al-Haqq (Yo soy la verdad) le condujo a la muerte (cfr. Massignon, The passion of Al-Hallaj). En el caso de Al-Mahad "se supone que murió en Samarcanda, Uzbekistán, cuando eran 'muchos sus días y más oscuras sus noches', con la 'fatiga de tanto polvo y de tantas espumas en su cabeza', y bajo las renovadas, aunque ya más débiles persecuciones de sus enemigos literatos, religiosos y políticos" (Ibargoyen, Cantos, 13).

En este sentido, ha llegado el momento de develar un secreto: AlMahad afortunadamente no ha muerto: vive entre nosotros. Sí, has in- 
tuido bien, lector atento: es el propio poeta uruguayo Saúl Ibargoyen (1930) quien se ha fundido con los poetas musulmanes de Damasco, Alejandría, Fez, Túnez, El Cairo y Bagdad, en el esplendor de la civilización musulmana, y ha creado esta poesía sublime; la misma que nos ha hecho viajar a través del desierto y del amor total. Aquella que nos comparte su experiencia de la Unidad con el Amado; tal como se refleja en este poema exquisito:

\author{
Cuando toques la espalda de la Amada \\ como si fuera una región del desierto \\ nacida de arenas dulcísimas, \\ que tus manos sean luminosas \\ de igual modo que la blanca mano \\ del Profeta cuyo nombre está \\ en los Libros venidos de la altura
}

(Cantos, 50).

Imagino tu sorpresa igual que la mía al enterarme de tal descubrimiento, lo que me hace pensar en la fusión alcanzada por este poeta contemporáneo con las imágenes poéticas y la narrativa que corresponden a una geografía física aparentemente tan lejana; y a la cual sus poemas nos acercan a través de una "geografía cualitativa", misma que nos descoloca de nuestras coordenadas de sentido habituales, abriendo así el espacio a una dimensión que nos permite estar en la sensación del desierto, y de una estética que por su excelsitud nos parece tan ajena.

Podemos buscar en la historicidad de este poeta, esto es, en su proceso y devenir de vida, algunas "huellas" y señales, siempre evasivas, que nos dan luces sobre este delirante encuentro con el lenguaje poético musulmán; y las avizoramos, sin duda, en la imagen del desierto, tomando prestadas las palabras de su paisano y también poeta, Eduardo Milán, quien describiendo el rostro de sus compañeros de exilio, nos habla de la "geografía cualitativa" (Solanes, Los nombres del exilio, 93-100) de aquellos que tuvieron que escapar de la dictadura militar en Uruguay: 
Plano y de una plenitud de espejismo, este desierto señala una nueva condición vacía. Señala también su margen un margen que comienza a contarse por la posibilidad de oír una voz. Entre esa voz — posibilidad emergente de una entrada de mar en la escritura - y el desierto como metáfora de una soledad muda hay un vagabundeo de alguien que, por falta de otro nombre, llamamos "poeta". Ahí está, en un espacio virtual y transitorio, no como un pez en el agua. Habría que insistir en el desierto ya que en el desierto lo único posible es insistir. Insistir: estar en estado de absoluta disponibilidad. No es posible clamar en el mar pero es posible reclamar en el desierto. Reclamar: estar en estado de escucha (Milán, Resistir, 15).

Saúl Ibargoyen, a través de Al-Mahad, es este poeta que clama y reclama al mundo: el gran despojo y borramiento de sentido eterno, ancestral; el enorme socavón que la guerra del Golfo Pérsico (19901991) abrió para la humanidad a través de la destrucción de ese espacio milenario, ubicado entre el Tigris y el Éufrates: cuna de la escritura, de las ciudades-estado. Este daño multidimensional tan grave y profundo, aún clama por una explicación, y en su lugar sólo encuentra un enorme silencio, y el sonido incesante de sus réplicas destructoras en casi todas las regiones del mundo.

Sobre esta continua pérdida y dolor, reclama Ibargoyen en La última bandera (1993), y en toda su extensa obra. En su sensibilidad poética, el mundo deviene en un plano paradójico de escasez y liminaridad, donde se hospedan las "emociones de aquellos que en el mundo no desean ningún otro status salvo el de desaparecido". Ya que lo que conocemos como mundo "existe sólo para seres que no tienen que estar preparados a cada instante para huir" (Sloterdijk, Extrañamiento del mundo, 101 y 320).

Es entonces, en esta suerte de desaparición y encuentro en el desierto musulmán, y a través de la cadencia de estos versos que recuperamos la memoria de nuestro hermoso legado ancestral, donde el vacío se ha llenado siempre de nuestros cantos y relatos inmersos en un tercer tiempo: entre el "tiempo del alma" y el "tiempo del mundo", un tiempo paradójico "cíclico e irreversible": la Eternidad (Ricoeur, Tiempo y narración I, 66-79). Aquí a partir del Absoluto se reencuentran los amantes y se vuelve al espacio iniciático, lugar de total placidez para el alma sosegada, como lo recitan estos hermosos versos del Corán: 
¡Oh Alma sosegada!,

Regresa a tu Señor, satisfecha y satisfactoria.

$\mathrm{Y}$ entra con Mis siervos,

Entra en Mi jardín

(Ghani, Corán, 89, 27-30)

La poesía de Al-Mahad nos coloca y recupera en ese espacio del desierto que fue abonado por poetas venidos de regiones remotas a rendirse ante el esplendor de la inmensidad. Es nuestra herencia, legado que Ibargoyen recupera para sí y para todos nosotros, mostrándonos la profundidad y diversidad de nuestra riqueza mística y poética, que nos sumerge en el oasis del Absoluto:
Ama a la amada
sin las obligaciones mundanas del corazón
Ámala sin sobrepasar los límites
que ese propio amor señala.
Debes amarla sin los gestos
que la tradición convoca.
La amarás omitiendo lo que ni ella
ni tú puedan comprender.
Así podrás desearla
a pesar de tu pasión

(Cantos, 54)

\section{REFERENCIAS}

Al-Jerrahi, Tosun Bayrak Sheikh y otros, Los Más Bellos Nombres de Allah, Córdoba, Junta islámica, 2006. Web [10/01/2013].

'Arabî, Ibn, Tratado de la Unidad, Málaga, Sirio, 1987.

Chevalier, Jean, El sufismo, Madrid, Fondo de Cultura Económica, 1987.

Corbin, Henry, La imaginación creadora en el sufismo de Ibn 'Arabî, Barcelona, Destino, 1993.

Corbin, Henry, Cuerpo espiritual y tierra celeste, Madrid, Siruela, 1996.

Heikal, Ahmad, "Curso de árabe", Alifnûn. Web [16/08/2013].

Ibargoyen, Saúl, La última bandera, México, Praxis, 1993. 
Ibargoyen, Saúl, Cantos a la amada. Muahmmud Ibn Al-Mahad, México, Praxis, 2009.

IBN YAZID, Al-Walid. "Diálogo". Poesía árabe clásica, Madrid, Mondadori, 1998.

Levinas, Emmanuel, Totalidad e Infinito. Ensayo sobre la exterioridad, Salamanca, Sígueme, 2006.

Massignon, Louis, The passion of Al-Hallaj: mystic and martyr of Islam, Princeton, Princenton University Press, 1994.

Milán, Eduardo, Resistir. Insistencias sobre el presente poético, México, Fondo de Cultura Económica, 2004.

Ricoeur, Paul, Tiempo y narración I. Configuración del tiempo en relato histórico, México, Siglo XXI, 2009.

Rocchetta, Carlo, Teología de la ternura. Un "evangelio" por descubrir, Salamanca, Ediciones Secretariado Trinitario, 2008.

Rumi. Diwan, citado en William C. Chittick La doctrina sufi de Rumi, Palma de Mallorca, José J. de Olañeta, 2008.

SAID, Edward W., Orientalismo, Madrid, Libertarias, 1990.

SLOTERDIJK, Peter, Extrañamiento del mundo, Valencia, Pretextos, 2001.

Solanes, José, Los nombres del exilio, Caracas, Monte Ávila, 1993. 